\title{
High density of fox and cat faeces in kitchen gardens and resulting rodent exposure to Echinococcus multilocularis and Toxoplasma gondii
}

\author{
Matthieu Bastien $^{1-3}$, Amélie Vaniscotte ${ }^{4}$, Benoit Combes ${ }^{3}$, Gérald Umhang ${ }^{5}$, Estelle Germain ${ }^{6}$, Valentin Gouley ${ }^{2}$, \\ Alice Pierlet $^{2}$, Thomas Quintaine ${ }^{1,2}$, Marie-Amélie Forin-Wiart ${ }^{1,2}$, Isabelle Villena ${ }^{1,7}$, Dominique Aubert ${ }^{1,7}$, Franck \\ Boué $^{5}$ and Marie-Lazarine Poulle ${ }^{1,2}$
}

\author{
${ }^{1}$ University of Reims Champagne-Ardenne, EA 3800 PROTAL, SFR Cap Santé, Reims cedex, France; \\ ${ }^{2}$ University of Reims Champagne-Ardenne, CERFE, Boult-aux-Bois, France; \\ ${ }^{3}$ French Establishment for Fighting Zoonoses (ELIZ), Domaine de Pixerécourt, Malzéville, France; \\ ${ }^{4}$ EcoDataDesign, France; \\ ${ }^{5}$ ANSES, Nancy Laboratory for Rabies and Wildlife, National Reference Laboratory for Echinococcus spp., Wildlife Eco- \\ epidemiology and Surveillance Unit, Malzéville, France; \\ ${ }^{6}$ Research and Observation Centre on Carnivores (CROC), Lucy, France; \\ ${ }^{7}$ University Hospital of Reims, Department of Parasitology-Mycology, National Reference Centre on Toxoplasma, Reims cedex, \\ France
}

\begin{abstract}
The faeces of the red fox, Vulpes vulpes (Linnaeus), and the domestic cat, Felis catus (Linnaeus), can be responsible for spreading eggs of Echinococcus multilocularis Leuckart, 1863 and oocysts of Toxoplasma gondii (Nicolle et Manceaux, 1908) into the environment. The accidental ingestion of these eggs or oocysts, through consumption of raw fruits or vegetables grown in or in contact with contaminated soil, can lead to alveolar echinococcosis (AE) or toxoplasmosis in humans. The present study provides a quantitative assessment of the faecal deposition by foxes and cats in kitchen gardens where fruits and vegetables are grown and its consequences for zoonosis transmission. The density of definitive host faeces is considered as one of the main factors in infection risk for intermediate hosts. The density of fox and cat faeces, as well as the prevalence of both AE and toxoplasmosis in rodent populations (contaminated by ingestion of eggs or oocysts), were compared within and outside kitchen gardens. Our results showed that the mean density of fox faeces did not significantly differ between kitchen gardens and habitat edges $\left(0.29 \pm 0.04\right.$ faeces $/ \mathrm{m}^{2} v s 0.22 \pm 0.02$ faeces $\left./ \mathrm{m}^{2}\right)$, the latter being known as an area of high fox faeceal densities. The density of cat faeces was significantly higher within the kitchen garden than outside $\left(0.86 \pm 0.22\right.$ faeces $/ \mathrm{m}^{2}$ vs $0.04 \pm 0.02$ faeces $\left./ \mathrm{m}^{2}\right)$. The sampled kitchen gardens might therefore be considered as possible hotspots for both fox and cat defecation. Of the 130 rodents trapped, 14\% were infected by at least one species of fox or cat intestinal parasite. These rodents were significantly more often infected when they were exposed to a kitchen garden. These results suggest that the deposit of fox and cat faeces in kitchen gardens would significantly impact the risk of human exposure to E. multilocularis and T. gondii. and should be prevented using effective means.
\end{abstract}

Keywords: rodent prevalence, food-borne agents, fox faeces density, cat faeces density, parasite transmission risk

Using relatively small cultivated plots of land devoted to growing food for human consumption is generally considered beneficial. These typical kitchen gardens provide herbs, fruits and vegetables that contribute to household health and food security (Marsh 1998, Finerman and Sackett 2003, Litt et al. 2011, Reyes-García et al. 2012). However, except for a small number of recent studies (Blaszkowska et al. 2011, Piarroux et al. 2013), little attention has been paid to the potential health risks associated with the contamination of kitchen gardens by food-borne agents, including the zoonotic parasites Echinococcus multilocularis Leuckart, 1863 and Toxoplasma gondii (Nicolle et Manceaux, 1908).

Echinoccocus multilocularis is responsible for human alveolar echinococcosis (AE), a rare but life-threatening helminthic zoonosis that is considered one of the most dangerous in the northern hemisphere (Eckert et al. 2011). Toxoplasma gondii is responsible for toxoplasmosis, 
a zoonosis that is usually subclinical, but may cause severe neurological or ocular disease in congenitally infected children, as well as neurological or ocular damage or even death in immunosuppressed patients (Dubie and Tere 2014, Robert-Gangneux et al. 2015). Both parasites reproduce in the intestines of the carnivores that are their definitive hosts, producing microscopic eggs (E. multilocularis) or oocysts (T. gondii) which are then excreted in the host's faeces. The faecal density from these definitive hosts therefore becomes one of the main factor of E. multiloc- ularis infection for any intermediate host (Giraudoux et al. 2003) and a factor of soil contamination with T. gondii (Afonso et al. 2008). In Europe, the red fox, Vulpes vulpes (Linnaeus), is the main definitive host of E. multilocularis (see Eckert and Deplazes 2004). Free-roaming domestic dogs, Canis lupus familiaris (Linnaeus), and domestic cats, Felis silvestris catus (Linnaeus), can also carry this parasite in their intestines, but these carnivores are not considered as responsible as red foxes for the excretion of eggs of E. multilocularis into the environment. Moreover, the prevalence of this parasite in dog populations is very low (Deplazes et al. 2004) and the excretion of its eggs in cats remains controversial (Kapel et al. 2006, Umhang et al. 2015, Knapp et al. 2016a). Felids are the only definitive host species for T. gondii, the domestic cat in general being the species implicated in western Europe (Gilot-Fromont et al. 2012).

Eggs of Echinococcus multilocularis and oocysts of T. gondii can remain viable and therefore infectious for months or even years, especially in the optimal environmental conditions of a low temperature and high humidity (Veit et al. 1995, Lélu et al. 2012, Federer et al. 2015). In Europe, the main intermediate hosts of E. multilocularis are the European water vole, Arvicola amphibious (Linnaeus), and meadow voles (Microtus spp.) (Eckert and Deplazes 2004). Around the world, all warm-blooded animals, including rodent, can act as intermediate hosts of T. gondii (see Tenter et al. 2000). While the prevalence of $\mathrm{AE}$ observed in rodent populations in endemic areas is generally low, i.e. less than 1-6\% (Eckert et al. 2011), higher infection rates for $T$. gondii in small rodents could be found. Depending on the species, the geographical area and the season, from $0 \%$ up to $73 \%$ of small rodents have been found to carry antibodies against $T$. gondii thus revealing past infection (Tenter et al. 2000). With regard to public health, an example source of human contamination (Cook et al. 2000, Kern et al. 2004) is the traces of DNA from E. multilocularis and T. gondii that have been detected in vegetables and fruit in contact with soil contaminated with eggs/oocysts (Lass et al. 2012, 2015). In short, faecal deposits from infected hosts found on domestic vegetable gardens could be a crucial risk amplifier of pre-harvest contamination of raw fruit and vegetables.

The present study investigated the potential epidemiological consequences of faecal deposits in kitchen gardens, considered as potential hotspots (high risk areas) for human exposure and therefore contamination, by food-borne pathogens. We assessed the density of fox and cat faeces and the occurrence of E. multilocularis and $T$. gondii in these faeces as well as the prevalence of both AE infection and $T$. gondii antibodies in rodent populations within and outside of kitchen gardens. We focused on rodent populations because rodents are known hosts for both $E$. multilocularis and $T$. gondii and because they can become infected, like humans, by ingesting the free-living stages of the parasites (Reperant et al. 2009). Infection with species of Hydatigera taeniaeformis (Batsch, 1786) was also considered because the eggs of these cestodes are also excreted by cats, dogs and foxes. This parasite is generally more prevalent in Europe than E. multilocularis and T. gondii. In Switzerland, H. taeniaeformis was found in $20 \%$ to $33 \%$ of all the Arvicola amphibious sampled in Zurich and in the canton of Geneva (Hofer et al. 2000, Reperant et al. 2009). In Austria, $22 \%$ of Microtus sp. and $30 \%$ of A. amphibious trapped were infected (Führer et al. 2010). Infection due to this species was thus used to provide a complete overview of environmental contamination sources that could result in rodent infection from canid and felid parasites spread by faeces.

\section{MATERIALS AND METHODS}

\section{Study area, host populations and prevalence}

The present study was based on data gathered from a survey conducted in 2013-2015 in a rural area of $650 \mathrm{~km}^{2}$ located in the Ardennes region of northeastern France $\left(49^{\circ} 25^{\prime} \mathrm{N}\right.$; $\left.04^{\circ} 50^{\prime} \mathrm{E}\right)$ as well as on data previously collected within the same region (Table 1). The human population density is low (around 16 inhabitants $/ \mathrm{km}^{2}$ ) and spread among villages, most of which have fewer than 200 inhabitants. Most of the villages lie close to woods or habitats that are generally used as retreat habitats by red foxes (Janko et al. 2012).

The fox density in the study area was approximately 3-4 foxes $/ \mathrm{km}^{2}$ during the 2003-2006 period (Guislain et al. 2007) while the prevalence of E. multilocularis in the fox population was 53\% during the 2001-2005 period (Guislain et al. 2008). The cumulative incidence rate in the region for human infection with AE during the 1982-2007 period was one of the highest reported in France (Piarroux et al. 2013), ranging between 2.74 and 6.10 . In the study area, $4.1 \%$ of the 710 rodents trapped during the 2010-2011 period carried antibodies against T. gondii (Gotteland et al. 2014). The meadow vole and the water vole are the main food sources for both red foxes and domestic cats in the study area (Guislain et al. 2008, Forin-Wiart 2014).

\section{Fox and cat faecal density \\ Sampling of fox and cat faeces outside kitchen gardens}

Fox faeces found outside kitchen gardens were collected during two sampling periods (sessions) in March and October, when the vegetation was sparse. These were in 2004 and 2005 (Guislain et al. 2007) and in 2007 and 2008 (Quintaine 2010). Two-metre wide transects were defined from which to collect and count fox faeces. These deposits were then identified by their shape and size. Transects were located in three types of habitat: arable land (1.9 ha sampled), grassland (3.2 ha sampled) and habitat edges (6.3 ha sampled). The habitat edges contained vegetation of varying heights, from almost ground level to two metres. The edges included road-side hard shoulders, stream banks and forest edges. The total surface area sampled was 11.4 ha. 
Table 1. Information about the dataset used to assess densities of fox and cat faeces inside and outside kitchen gardens.

\begin{tabular}{|c|c|c|c|c|c|c|}
\hline Study & Goal & Definitive host & $\begin{array}{l}\text { Host faeces } \\
\text { identification }\end{array}$ & Sampled habitat & Period of collect & $\begin{array}{l}\text { Parasite detec- } \\
\text { tion in faeces }\end{array}$ \\
\hline $\begin{array}{l}\text { Guislain et al. } \\
\text { (2007) } \\
\text { Quintaine (2010) }\end{array}$ & $\begin{array}{l}\text { Investigate the overlap between the spatial } \\
\text { distributions of voles and fox faeces in } \\
\text { relation with the transmission dynamics } \\
\text { of Echinococcus multilocularis }\end{array}$ & $\begin{array}{l}\text { red fox } \\
\text { (Vulpes vulpes) }\end{array}$ & visual & $\begin{array}{l}\text { arable land, grass- } \\
\text { land, habitat edges }\end{array}$ & $\begin{array}{l}\text { March, October } \\
\text { 2004, } 2005 \\
\text { March, October } \\
2007,2008\end{array}$ & - \\
\hline Forin-Wiart (2014) & $\begin{array}{l}\text { Evaluate differences in the exploitation of } \\
\text { food items by free-ranging domestic cats }\end{array}$ & $\begin{array}{l}\text { domestic cat } \\
\text { (Felis s. catus) }\end{array}$ & $\begin{array}{l}\text { molecular } \\
\text { (genotyping) }\end{array}$ & $\begin{array}{l}\text { two villages } \\
\text { (Boult-aux-Bois } \\
\text { and Briquenay) } \\
\text { and their surround- } \\
\text { ing pastures and } \\
\text { meadows }\end{array}$ & $\begin{array}{l}\text { November- } \\
\text { December } 2011 \text {, } \\
\text { March } 2012\end{array}$ & - \\
\hline Present study & $\begin{array}{l}\text { Assess the fox and cat densities in kitchen } \\
\text { gardens and the rodent exposure to their } \\
\text { parasites }\end{array}$ & fox, cat & $\begin{array}{l}\text { molecular } \\
\text { (qPCR) }\end{array}$ & kitchen gardens & $\begin{array}{l}\text { March, October } \\
2014,2015\end{array}$ & $\begin{array}{l}\text { E. multilocu- } \\
\text { laris, } \\
\text { Toxoplasma } \\
\text { gondii }\end{array}$ \\
\hline
\end{tabular}

Cat faeces found outside kitchen gardens were collected during two, one-week sessions in November-December 2011 and March 2012 (Umhang et al. 2015). Sample transects were defined in the surrounding pastures and meadows of two villages, Boultaux-Bois and Briquenay (see Forin-Wiart et al. 2014 for the method). A total surface area of 1.8 ha was sampled. Cat faeces were first visually identified in the field by their shape and size, then accurately identified using molecular analysis for host species (Table 1).

\section{Sampling of fox and cat faeces inside kitchen gardens}

From 2013 to 2015, 43 private kitchen gardens located in eight villages were examined four times for the presence of cat and fox faeces. These gardens were used uniquely for growing food (not ornamental plants) for household consumption, providing vegetables and fruits such as lettuce, potatoes, carrots, leeks, cabbages, aromatic herbs, strawberries, etc. These gardens were set close to the house; they had open access to foxes and cats due to the absence of continuous fencing. When comparing the density of cat faeces inside and outside kitchen gardens, only the faeces collected in kitchen gardens located in Boult-aux-Bois and Briquenay, were considered in the analysis.

Sampling was undertaken in October and March, outside of the gardening period to avoid damage to seedlings. Whatever the surface of the garden, each survey consisted of a visual scan of the whole garden surface along all pre-defined transects. Fox, cat or unidentified faeces were first identified visually in the field on the basis of their shape and size, and were later accurately identified by molecular analysis for host species (see following section). All collected faeces were decontaminated for five days at $-80^{\circ} \mathrm{C}$ and stored at $-20^{\circ} \mathrm{C}$ before analysis. The size of the kitchen gardens sampled ranged from $16 \mathrm{~m}^{2}$ to $1,794 \mathrm{~m}^{2}$, for a total sampled surface area of 5.9 ha.

\section{Molecular analysis on faeces}

A quantity of $0.5 \mathrm{~g}$ of each copro-sample was subjected to DNA extraction as previously reported (Knapp et al. 2014) using the QIAamp Fast DNA Stool Mini Kit (Qiagen, Hilden, Germany) and following manufacturer recommendations. The DNA from carnivore host species (fox, cat, dog) and from E. multilocularis were identified by carrying out a multiplex real-time PCR assay using the protocol described in Knapp et al. (2016b). DNA extracts were then subjected to a real-time quantitative PCR (qPCR) following the procedure described by Lélu et al. (2011) in order to detect DNA of $T$. gondii. Negative controls were included from DNA extraction to PCR amplification steps, and each PCR run contained both negative and positive controls. No amplification results were purposefully obtained for the negative control. A qPCR with a $\mathrm{Cq} \leq 45$ cycles allowed us to determine the presence of parasites.

\section{Inter-annual variability of fox and cat densities}

Since the comparison of fox faecal density within and outside of kitchen gardens was performed on data collected during two different time periods separated by ten years, variability in fox population density over this period could partly explain any difference in faecal density observed between habitats. To take this effect into account, significant changes in the mean number of hunted foxes per hunting period and per village were considered as a proxy for the temporal variability of fox density and were compared between the two sampling periods using a Wilcoxon, Mann and Whitney rank sum test. The number of hunted foxes per hunting period (winter) and per village was provided by the local Hunting Agency (Fédération départementale des chasseurs des Ardennes). The inter-annual cat population density was considered stable during the whole study period since the turnover rate in the cat population of Boult-aux-Bois and Briquenay was close to one during the 2008-2012 period (Lélu 2010, Gotteland 2013, Forin-Wiart 2014).

\section{Rodent trapping, necropsy and parasite detection Rodent trapping}

Rodent trapping was designed to target Arvicola amphibious and Microtus sp., but bank voles, Myodes glareolus (Schreber) and field mice (Apodemus sp.) were also captured. In April 2015, trapping was simultaneously conducted in 25 sites located in 100 $\mathrm{m}$ buffer zones around kitchen gardens and in a further 25 sites located outside $200 \mathrm{~m}$ buffer zones. In May 2016, a second trapping session was simultaneously conducted in 15 other sites located in $100 \mathrm{~m}$ buffer zones around kitchen gardens and in 10 sites located outside $200 \mathrm{~m}$ buffer zones. The selection of trapping sites was based on the presence of holes and grass tracks, which are characteristic of the habitat of Microtus sp., and on earth monticules, which are characteristic of the habitat of Arvicola amphibious (see Giraudoux et al. 1995). Arvicola amphibious was trapped with Topcat traps (TOPCAT, GmbH, Wintersingen, Switzerland) set up near monticules for three consecutive nights and checked once a day. Individuals from Microtus sp. were trapped with INRA live traps $(5 \mathrm{~cm} \times 5 \mathrm{~cm} \times 15 \mathrm{~cm}$ box $)$, which also allowed 
the capture of Myodes glareolus and Apodemus sp. In each of the 75 selected trapping sites, 34 INRA traps were set up in a line at intervals of three meters for three consecutive nights and checked once a day, as per the standardised method of Spitz et al. (1974). Thus, a total of 65 Topcat traps and 1,350 INRA traps were set up in the $100 \mathrm{~m}$ buffer zones around kitchen gardens, and 69 Topcat traps and 1,156 INRA traps were set up outside the $200 \mathrm{~m}$ buffer zone.

The geographical coordinates of each trapped animal were recorded using a global positioning system (GPS). The distance from this trapping point to the nearest kitchen garden was then calculated using the 'rgdal' package (Bivand et al. 2014) in order to classify trapped rodents as 'exposed' or 'not exposed' to parasites potentially spread by red fox or cat faeces in a kitchen garden. The exposure/non-exposure variable was considered dependent on the mean movement range of individuals: $20 \mathrm{~m}$ for Microtus arvalis (Pallas) - see Briner et al. (2005), $31 \mathrm{~m}$ for Microtus agrestis (Linnaeus) - see Pusenius and Viitala (1993), $40 \mathrm{~m}$ for Apodemus sp. - see Vukicevic-Radic et al. (2006), $80 \mathrm{~m}$ and $130 \mathrm{~m}$ for A. amphibious females and males respectively (Stoddart 1970), and $135 \mathrm{~m}$ for Myodes glareolus - see Kozakiewicz et al. (1993). If the distance between a rodent's capture location and the barycentre of the nearest kitchen garden was inferior or equal to the mean movement range reported for the species, the individual was considered 'exposed'. Otherwise, it was considered 'not exposed'.

\section{Rodent necropsy}

Each trapped rodent was specifically identified on the basis of its size, morphology and dental characteristics with the aid of a reference manual (Marchesi et al. 2008). It was then weighed, sexed, dissected and classified as adult or juvenile according to the maturity of its reproductive organs. Hearts were submerged in $1 \mathrm{ml}$ of miliQ water and fluids were stored at $20^{\circ} \mathrm{C}$ until analysis. In the case of the presence of lesions on the liver, samples were collected and stored at $-20^{\circ} \mathrm{C}$ until molecular analysis.

\section{Serological diagnosis of Toxoplasma gondii}

Heart fluids were tested for the presence of antibodies against antigen of $T$. gondii using a modified agglutination test specific to IgG antibodies (Dubey and Desmonts 1987) and with antigen prepared at the Laboratory of Parasitology-Mycology, Reims. A two-fold dilution was used for the serum, starting at $1: 3$ dilution. The $1: 6$ dilution was used as the threshold for the analysis of serological results as suggested by Gotteland et al. (2014).

\section{PCR diagnosis of rodent livers for Echinococcus multilocula-} ris and Hydatigera taeniaeformis

The DNA from sampled parasitic lesions was extracted using the iPrep purification instrument (Invitrogen, iPrep ChargeSwitch gDNATissue Kit, Carlsbad, CA, USA). A multiplex PCR assay using two couples of primers was carried out to diagnose E. multilocularis (Cest1-2) and species of Taenia following Trachsel et al. (2007). Sequencing was performed to identify the species involved after comparison with the nucleotide sequences available in GenBank.

\section{Data analysis}

Analyses were performed using the statistical software program R 3.1.3 (R Core Team 2015). Confidence intervals (95\%) around prevalences were assessed using a procedure given in Agresti and Coull (1998).

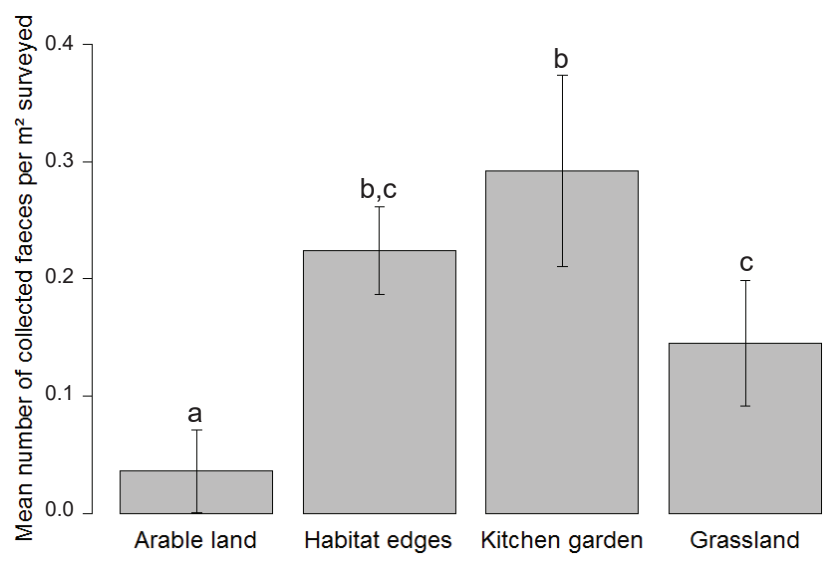

Fig. 1. Mean number of red fox faeces collected per $\mathrm{m}^{2}$ surveyed $(+/-95 \% \mathrm{CI})$ in arable land, habitat edges, kitchen gardens and grassland, assessed both from collections taken in the present study and from previous studies in the same study area by Guislain et al. (2007) and Quintaine (2010). Letters a-c correspond to statistical differences between habitat tested according to the Dunn's Post hoc test.

\section{Fox and cat faecal density within and outside kitchen gardens}

Faecal density (i.e. the number of faeces found / sampled within a given surface area in $\mathrm{m}^{2}$ ) was calculated per transect (for outside garden sampling) or per kitchen garden (for within garden sampling), per sampling session and per habitat (i.e. arable land, grassland, habitat edges and kitchen gardens).

Fox faecal densities were generally compared between habitats using a Kruskal-Wallis rank sum test followed by Dunn's Post hoc pairwise tests between habitats. Cat faecal densities within and outside kitchen gardens in Boult-aux-Bois and Briquenay were compared using a Wilcoxon, Mann and Whitney rank sum test.

\section{Prevalence of rodents exposed and not exposed to kitchen gardens}

The prevalence of rodents having ingested eggs or oocysts was compared between those exposed and those not exposed to a kitchen garden using a Chi-squared test. In order to test that there was no confusing variable due to unbalanced sampling, the prevalence of rodents having ingested eggs or oocysts was also compared between adults and juveniles using a Fisher exact test for count data. In the same way, the prevalence of positive rodents was compared between the three parasites using a Fisher exact test for count data.

\section{RESULTS}

Within kitchen gardens, 88 fox faeces and 141 cat faeces were collected whereas 206 fox faeces and 261 cat faeces were collected outside. Out of the 229 faeces collected inside, $186(81 \%)$ were visually attributed to cat and fox, and the remaining 43 (19\%) were unidentified in the field. Molecular analysis was used to confirm the host species of all the samples. Out of the 43 unidentified faeces: 16 were attributed to fox (totaling 18\% confirmed by molecular analyses) and 27 were attributed to cat (totaling 19\% confirmed by molecular analyses). Finally, 22 fox faeces $(25 \%$ of those confirmed by molecular analysis) were misclassified to cat in the field and 14 (10\% of those confirmed by molecular analysis) were misclassified to fox in the field. 


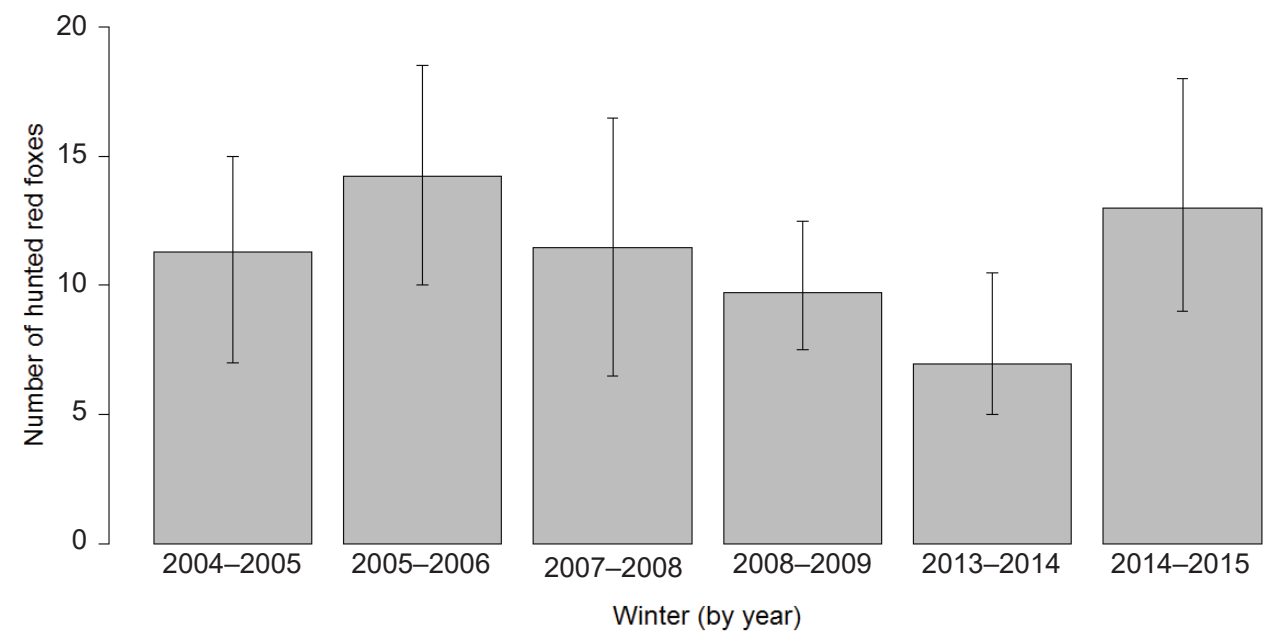

Fig. 2. Mean number of red foxes hunted per winter in the study area during the sampling period (mean $+/-95 \%$ CI).

Table 2. Occurrence of rodents according to their exposure to kitchen gardens, their species and their infectious status. If the distance between a rodent's capture location and the barycentre of the nearest kitchen garden was inferior or equal to the mean movement range reported for the species, the individual was considered 'exposed'. Otherwise, it was considered 'not exposed'. Percentages are provided with their $95 \% \mathrm{CI}$.

\begin{tabular}{|c|c|c|c|c|c|c|}
\hline & Species & Trapped & Infected & $\begin{array}{c}\text { Infected by } \\
\text { Echinococcus } \\
\text { multilocularis (PCR) }\end{array}$ & $\begin{array}{c}\text { Infected by } \\
\text { Toxoplasma gondii } \\
\text { (antibodies detection) }\end{array}$ & $\begin{array}{l}\text { Infected by } \\
\text { Hydatigera taeniaeformis } \\
\text { (PCR) }\end{array}$ \\
\hline \multirow{5}{*}{ Exposed } & Arvicola terrestris & 33 & 9* & 2 & 2 & 6 \\
\hline & Microtus sp. & 6 & 1 & 0 & 1 & 0 \\
\hline & Myodes glareolus & 4 & 1 & 0 & 1 & 0 \\
\hline & Apodemus sp. & 14 & 2 & 1 & 0 & 1 \\
\hline & Total & 57 & $13(23 \%)[13.8-35.2]$ & $3(5 \%)[1.8-14.3]$ & $4(7 \%)[2.1-17.1]$ & $7(12 \%)[6.1-23.2]$ \\
\hline \multirow{5}{*}{ Not exposed } & A. terrestris & 14 & 1 & 0 & 0 & 1 \\
\hline & Microtus sp. & 26 & 4 & 2 & 0 & 2 \\
\hline & Myodes glareolus & 5 & 0 & 0 & 0 & 0 \\
\hline & Apodemus sp. & 28 & 0 & 0 & 0 & 0 \\
\hline & Total & 73 & $5(7 \%)[2.9-15.0]$ & $2(3 \%)[0.7-9.4]$ & 0 & $3(4 \%)[1.4-11.4]$ \\
\hline
\end{tabular}

* One Arvicola terrestris exposed to a potentially contaminated kitchen garden tested positive for both the presence of DNA of Echinococcus multilocularis and antibodies against antigens of Toxoplasma gondii.

The mean density of fox faeces varied significantly according to the habitat (Kruskal-Wallis rank sum test: $\chi^{2}=19.712, \mathrm{df}=3, \mathrm{P}<0.001 ;$ Fig. 1). However, it did not vary significantly between kitchen gardens and habitat edges $\left(0.29 \pm 0.04\right.$ faeces $/ \mathrm{m}^{2}$ and $0.22 \pm 0.02$ faeces $/ \mathrm{m}^{2}$, respectively; Dunn's Post hoc test; $\mathrm{P}=0.959$ ), but was significantly higher in kitchen gardens than in grasslands $(0.14 \pm 0.03$; Dunn's Post hoc test; $\mathrm{P}=0.017)$ or than in arable lands ( $0.04 \pm 0.02$; Dunn's Post hoc test; $\mathrm{P}<0.001)$. The mean density of cat faeces was significantly higher inside than outside kitchen gardens $\left(0.86 \pm 0.22\right.$ faeces $/ \mathrm{m}^{2}$ and $0.04 \pm 0.02$ cat faeces $/ \mathrm{m}^{2}$, respectively; $\mathrm{W}=1,700$; $\mathrm{P}<0.001)$.

Inside kitchen gardens, 21 of the 88 fox faeces collected (prevalence $24 \%, 95 \% \mathrm{CI}=16.1-33.7$ ) were positive for the presence of E. multilocularis DNA and six out of the 141 cat faeces $(4 \%, 95 \% \mathrm{CI}=2.0-9.0)$ positive for the presence of DNA of T. gondii. No fox faecal sample was found to be positive for $T$. gondii whereas two cat faeces were positive for DNA of E. multilocularis.

The mean numbers of trapped foxes did not differ significantly between time periods (Kruskal-Wallis rank sum test: $\chi^{2}=10.607, \mathrm{df}=5, \mathrm{P}=0.060$; Fig. 2), although a lower mean number of foxes was recorded for the winter of 2013-2014 compared with other winters (Fig. 2).

A total of 130 rodents were trapped: 47 Arvicola amphibious, 42 Apodemus sp., 32 Microtus sp. and nine Myodes glareolus (Table 2). Out of the 57 rodents exposed to kitchen gardens potentially contaminated by fox and cat faeces, $13(23 \%, 95 \% \mathrm{CI}=13.8-35.2)$ tested positive for at least one of the three parasites. This was significantly different from the five out of 73 rodents $(7 \%, 95 \%$ $\mathrm{CI}=2.9-15.0)$ not exposed to kitchen gardens that tested positive (Table 2, $\chi^{2}=2.61, \mathrm{df}=1, \mathrm{P}=0.105$ ).

DNA of Echinococcosis multilocularis was detected by PCR in five out of 130 trapped rodents $(4 \%, 95 \%$ $\mathrm{CI}=1.7-8.7) ;$ E. multilocularis prevalence was found to be higher in rodents exposed to kitchen gardens $(5 \%, 95 \%$ $\mathrm{CI}=1.8-14.3)$ than for the rodents not exposed $(3 \%, 95 \%$ $\mathrm{CI}=0.7-9.4$ ) (Table 2 for details). The three 'exposed' rodents that were positive for E. multilocularis were trapped close to three different kitchen gardens, two of which were located in the same village. 
Antibodies against antigens of $T$. gondii were found in four out of 130 trapped rodents $(3 \%, 95 \% \mathrm{CI}=1.2-7.6)$; all four were exposed to different kitchen gardens in the same village. With primers used to detect species of Taenia from liver lesions, only Hydatigera taeniaeformis sequences were amplified. Of the 57 rodents considered to be exposed to potentially contaminated kitchen gardens, seven $(12 \%$, $95 \% \mathrm{CI}=6.1-23.2)$ tested positive for $H$. taeniaeformis in contrast to three out of 73 rodents $(4 \%, 95 \% \mathrm{CI}=1.4-11.4)$ not exposed to kitchen gardens. The seven rodents were tested positive for the presence of $H$. taeniaeformis were trapped close to six different kitchen gardens; two rodents were trapped in the same kitchen garden. One Arvicola amphibious exposed to a potentially contaminated kitchen garden was positive for both DNA of E. multilocularis and antibodies against antigens of $T$. gondii.

Adult rodents were not significantly more infected by H. taeniaeformis or E. multilocularis, or more in contact with $T$. gondii compared to juvenile rodents (Fisher exact tests, $\mathrm{OR}=0, \mathrm{P}=0.12, \mathrm{OR}=0.76, \mathrm{P}=1$ and $\mathrm{OR}=3.17$, $\mathrm{P}=0.25$, respectively). Likewise, no significant differences were found between species in terms of contamination rate by $H$. taeniaeformis or E. multilocularis (Fisher exact test, $\mathrm{P}=0.19$ and $\mathrm{P}=0.89$, respectively), nor in terms of the presence of antibodies against $T$. gondii antigen (Fisher exact tests, $\mathrm{P}=0.09$ ).

\section{DISCUSSION}

Previous studies have shown the amplification of DNA with primers theoretically calibrated to be specific to Echinococcus multilocularis and Toxoplasma gondii from fruits and vegetables harvested in cultivated lands (Lass et al. 2012, 2015). In addition, in the present study, we found that fox and cat faeces are more contaminated with these parasites within than outside kitchen gardens. Our study therefore emphasises that kitchen gardens might be micro-foci of potential infection of humans with E. multilocularis and $T$. gondii. Indeed, spatial heterogeneity of the probability of infection of intermediate hosts with E. multilocularis at a local scale has been reported in rural areas (Giraudoux et al. 2002) as well as urban areas (Hofer et al. 2000, Reperant et al. 2009, Robardet et al. 2011).

Distribution of fox faeces is known to be one of the factors that can give rise to micro-foci of transmission of E. multilocularis (see Giraudoux et al. 2002). Similarly, environmental contamination with $T$. gondii has been described as highly heterogeneous at the local scale and driven in large part by the spatial distribution of cat faeces (Afonso et al. 2008, Simon et al. 2017).

We showed that the mean density of fox faeces within kitchen gardens did not significantly differ from that found along habitat edges known as hotspots of fox faeces deposition in comparison to other habitats (Giraudoux et al. 2002, Guislain et al. 2007). This result confirms the important role that kitchen gardens might play in human infection with food-borne parasites we studied. However, this conclusion might need to be adjusted regarding some bias inherent to fox faeces identification collected within and outside kitchen gardens, which was performed by dif- ferent researchers in the only frame of this study. Among the faeces collected inside kitchen gardens, 24\% were misclassified to fox while $38 \%$ attributed to fox by molecular analyses were visually misclassified as dog or cat.

While the identification of fox faeces collected outside kitchen gardens was not confirmed by molecular analyses, one can assume that the bias in visual discrimination in those areas might be similar than the one identified inside kitchen gardens. Ultimately, one can assume that visually misclassified faeces compensate uncollected fox faeces (thinking it was from dog or cat). Despite this bias, the mean density of fox faeces found outside kitchen gardens was sufficiently large so that we could consider kitchen gardens as a non-negligible spot for fox defecation.

It has been showed that the density of fox faeces can be influenced by fox population density (Pleydell et al. 2004). Assuming that fox hunting data provide information on significant variations of fox densities, differences in fox faecal densities between kitchen gardens and other habitats observed in this study cannot be explained, at least fully, by fox density variation over the study periods. In Germany, Janko et al. (2012) showed that fox density increases by a factor of 3-8 in rural villages compared to strictly rural areas. They postulated that villages and small towns offer enough resources to foxes to reduce their home range if suitable retreat habitats (such as patches of woodland or vegetation) are present in their vicinity.

In our study area, most of the villages were close to a retreat habitat; they also contained potential food sources for foxes such as poultry, orchards or compost heaps. Moreover, most of the kitchen gardens were located in the vicinity of open fields, which offer a suitable habitat for voles. As a result, the fox density at night, when they forage, is probably higher within villages than outside of them, at least from October to March when most of the villagers are inside their homes before nightfall. The high fox density in villages where kitchen gardens are located, coupled with the high food supply for foxes around kitchen gardens which can result in frequent faecal depositions since the intensity of defecation by a fox is linked to its food consumption during the previous hours (Goszczyński 1990) - may contribute to the high density of fox faeces observed in kitchen gardens.

However, the mean density of cat faeces, whose specific identification was confirmed for both inside and outside samples, was much higher in kitchen gardens than outside. In this way, kitchen gardens can also be considered as a hotspot for cat faecal deposits. This finding may be partly explained as a result of cats preferring to defecate in loose soil for ease of burying their faeces (Afonso et al. 2008).

The high density of fox and cat faeces within kitchen gardens led us to expect that these could be areas at risk of transmitting E. multilocularis and T. gondii to intermediate hosts. Our results on rodent infection seem to confirm this hypothesis: intermediate host rodents exposed to kitchen gardens potentially contaminated by fox or cat faeces were more often infected by or have been more often in contact with fox or cat intestinal parasites than rodents not exposed to these gardens. 
This result might need to be discussed regarding the bias inherent to the two different methods used to detect parasites. Indeed, serological diagnosis would probably be more sensitive that PCR diagnosis. However, this bias would be the same for rodents 'exposed' or 'not exposed' to a kitchen garden. Therefore, we conclude that using a combination of methods to estimate a global prevalence for rodents 'exposed' and 'not exposed' to kitchen gardens, did not strongly affect our results, although the values of prevalence might be underestimated.

Another factor increasing the infection risk in kitchen gardens could be the length of the parasites' infectious stage in the environment. Kitchen gardens may provide particularly suitable conditions for taeniid eggs (including E. multilocularis) and oocysts of T. gondii as they are watered during the dry summer period and desiccation is thought to critically hamper the viability of these eggs and oocysts (Lélu et al. 2012, Federer et al. 2015). The high density of fox and cat faeces in addition to the ideal conditions for the preservation of parasite eggs may explain why rodents exposed to potentially contaminated kitchen garden soil are 3.5 times more likely to be infected with fox and cat intestinal parasites than rodents not exposed to these gardens.

\section{REFERENCES} S., Thulliez P., Villena I., Aubert D., Rabilloud M., Riche B., Gilot-Fromont E. 2008: Spatial distribution of soil contamination by Toxoplasma gondii in relation to cat defecation behaviour in an urban area. Int. J. Parasitol. 38: 1017-1023.

Agresti A., Coull B.A. 1998: Approximate is better than "exact" for interval estimation of binomial proportions. Am. Stat. 52: 119-126.

Bivand R., Keitt T., Rowlingson B. 2014: rgdal: Bindings for the geospatial data abstraction library. R package version 1.2-16, https://CRAN.R-project.org/package=rgdal, 11/2017.

Blaszkowska J., Kurnatowski P., Damiecka P. 2011: Contamination of the soil by eggs of geohelminths in rural areas of Lodz district (Poland). Helminthologia 48: 67-76.

Briner T., Nentwig W., Airoldi J.-P. 2005: Habitat quality of wildflower strips for common voles (Microtus arvalis) and its relevance for agriculture. Agric, Ecosyst. Environ. 105: 173-179.

Cook A.J.C., Gilbert R.E., Buffolano W., Zufferey J., Petersen E., Jenum P.A., Foulon W., Semprini A.E., Dunn D.T., Congenital E.R.N. 2000: Sources of Toxoplasma infection in pregnant women: European multicentre case-control study. Br. Med. J. 321: 142-147.

Deplazes P., Hegglin D., Gloor S., Romig T. 2004: Wilderness in the city: the urbanization of Echinococcus multilocularis. Trends Parasitol. 20: 77-84.

Dubey J.P., Desmonts G. 1987: Serological responses of equids fed Toxoplasma gondii oocysts. Equine Vet. J. 19: 337-339.

Dubie T., Tere G. 2014: Toxoplasmosis: epidemiology with the emphasis of its public health importance. MRJMMS 2: 97-108.

Eckert J., Deplazes P. 2004: Biological, epidemiological, and clinical aspects of echinococcosis, a zoonosis of increasing concern. Clin. Microbiol. Rev. 17: 107-135.

Eckert J., Deplazes P., Kern P. 2011: Alveolar echinococcosis (Echinococcus multilocularis) and Neotropical forms of echinococcosis (Echinococcus vogeli and Echinococcus oligarthrus). In: S.R. Palmer, L. Soulsby, P. Torgerson and D.W.G. Brown
Afonso E., Lemoine M., Poulle M.-L., Ravat M.-C., Romand
To conclude, the risk of transmission to humans of the parasites is a concern, as the high densities of fox and cat faeces already contaminated by E. multilocularis and T. gondii were found in kitchen gardens. Moreover, the prevalence of parasitic infection in rodents was higher inside kitchen gardens than outside, thus demonstrating the efficiency of the transmission cycle of both E. multilocularis and T. gondii in kitchen gardens. As far as we know, no data are available on the amount of eggs or oocysts required to infect humans. However, since kitchen gardens are used to grow vegetables, which are often eaten raw, and considering that eggs or oocysts can probably be left on fruit and vegetables in contact with contaminated soil (Lass et al. 2012, 2015), measures should be taken to prevent carnivores from depositing faeces within these cultivated areas.

Acknowledgements. We are very grateful to those who allowed us to access their private kitchen gardens. We are also indebted to S. Debrielle, Q. Gutknecht and A. Merieau, from the Fédération des Chasseurs des Ardennes, for providing data about fox hunting. Many thanks to Regine Geers, Vanessa Hormaz, Jean-Marc Boucher, Christophe Caillot and Camille Renault for their contribution to laboratory analysis, and to Elise Bradbury and Sarah Mackenzie for the English editorial reviews. Financial support for this study was provided by the Conseil Général des Ardennes.
(Eds.), Oxford Textbook of Zoonoses Biology, Clinical Practice, and Public Health Control. Oxford University Press, Oxford, pp. 669-699.

Federer K., Armua-Fernandez M.T., Hoby S., Wenker C., DePlazeS P. 2015: In vivo viability of Echinococcus multilocularis eggs in a rodent model after different thermo-treatments. Exp. Parasitol. 154: 14-19.

Finerman R., Sackett R. 2003: Using home gardens to decipher health and healing in the Andes. Med. Anthropol. Q. 17: 459-482.

FORIN-WiART M.-A. 2014: Identification des facteurs de variation de la prédation exercée par les chats domestiques (Felis silvestris catus) en milieu rural. PhD thesis, Reims Champagne Ardenne University, Reims, 268 pp.

Forin-Wiart M.-A., Gotteland C., Gilot-Fromont E., Poulle M.-L. 2014: Assessing the homogeneity of individual scat detection probability using the bait-marking method on a monitored free-ranging carnivore population. Eur.J. Wildl. Res. 60: 665-672.

Führer H.-P., Schneider R., Walochnik J., Auer H. 2010: Extraintestinal helminths of the common vole (Microtus arvalis) and the water vole (Arvicola terrestris) in western Austria (Vorarlberg). Parasitol. Res. 106: 1001-1004.

Gilot-Fromont E., Lélu M., Dardé M.-L., Richomme C., Aubert D., Afonso E., Mercier A., Gotteland C., VilLENA I. 2012: The life cycle of Toxoplasma gondii in the natural environment. In: O. Djurkovi Djakovi (Ed.), Toxoplasmosis - Recent Advances. InTech: 3-36, Available from: https:// www.intechopen.com/books/toxoplasmosis-recent-advances/ the-life-cycle-of-toxoplasma-gondii-in-the-natural-environment

Giraudoux P., Craig P.S., Delattre P., Bao G., Bartholomot B., Harraga S., Quéré J.-P., Raoul F., Wang Y., Shi D., Vuitton D.A. 2003: Interactions between landscape changes and host communities can regulate Echinococcus multilocularis transmission. Parasitology 127: S121-S131. 
Giraudoux P., Delattre P., Takahashi K., Raoul F., Quéré J.P., Craig P., Vuitton D., Pawlowski Z. 2002: Transmission ecology of Echinococcus multilocularis in wildlife: what can be learned from comparative studies and multiscale approaches? In: Proceedings of the NATO Advanced Research Workshop on Cestode Zoonoses: Echinococcosis and Cysticercosis: An Emergent and Global Problem, Poznań, Poland, 10-13 September 2000. IOS Press, pp. 251-266.

Giraudoux P., Pradier B., Delattre P., Deblay S., Salvi D., Defaut R. 1995: Estimation of water vole abundance by using surface indices. Acta Theriol. 40: 77-96.

GoszcZyŃski J. 1990: Scent marking by red foxes in Central Poland during the winter season. Acta Theriol. 35: 7-16.

GotTeland C. 2013: Dynamique spatio-temporelle de la contamination environnementale par Toxoplasma gondii. $\mathrm{PhD}$ thesis, Reims Champagne Ardenne University, Reims, 245 pp.

Gotteland C., Chaval Y., Villena I., Galan M., Geers R., Aubert D., Poulle M.-L., Charbonnel N., Gilot-FromONT E. 2014: Species or local environment, what determines the infection of rodents by Toxoplasma gondii? Parasitology 141: 259-268

Guislain M.-H., Raoul F., Giraudoux P., Terrier M.-E., Froment G., Ferte H., Poulle M.-L. 2008: Ecological and biological factors involved in the transmission of Echinococcus multilocularis in the French Ardennes. J. Helminthol. 82: 143-151.

Guislain M.-H., Raoul F., Poulle M.L., Giraudoux P. 2007: Fox faeces and vole distribution on a local range: ecological data in a parasitological perspective for Echinococcus multilocularis. Parasite 14: 299-308.

Hofer S., Gloor S., Müller U., Mathis A., Hegglin D., Deplazes P. 2000: High prevalence of Echinococcus multilocularis in urban red foxes (Vulpes vulpes) and voles (Arvicola terrestris) in the city of Zürich, Switzerland. Parasitology 120: $135-142$.

Janko C., Schröder W., Linke S., KöNig A. 2012: Space use and resting site selection of red foxes (Vulpes vulpes) living near villages and small towns in southern Germany. Acta Theriol. 57: 245-250.

Kapel C.M.O., Torgerson P.R., Thompson R.C.A., Deplazes P. 2006: Reproductive potential of in experimentally infected foxes, dogs, raccoon dogs and cats. Int. J. Parasitol. 36: 79-86.

Kern P., Ammon A., Kron M., Sinn G., Sander S., Peters- en L.R., Gaus W., Kern P. 2004: Risk factors for alveolar echinococcosis in humans. Emerg. Infect. Dis. 12: 2088-2093.

Knapp J., Millon L., Mouzon L., Umhang G., Raoul F., Ali Z.S., Combes B., Comte S., Gbaguidi-Haore H., GreNouillet F., Giraudoux P. 2014: Real time PCR to detect the environmental faecal contamination by Echinococcus multilocularis from red fox stools. Vet. Parasitol. 201: 40-47.

Knapp J., Combes B., Umhang G., Aknouche S., Millon L. 2016a: Could the domestic cat play a significant role in the transmission of Echinococcus multilocularis? A study based on qPCR analysis of cat feces in a rural area in France. Parasite 23: 42.

Knapp J., Umhang G., Poulle M.-L., Millon L. 2016b: Development of a Real-Time PCR for a sensitive one-step coprodiagnosis allowing both the identification of carnivore feces and the detection of Toxocara spp. and Echinococcus multilocularis. App. Environ. Microbiol. 82: 2950-2958.

Kozakiewicz M., Kozakiewicz A., Łukowski A., Gortat T. 1993: Use of space by bank voles (Clethrionomys glareolus) in a Polish farm landscape. Landsc. Ecol. 8: 19-24.

Lass A., Pietkiewicz H., Szostakowska B., Myjak P. 2012 The first detection of Toxoplasma gondii DNA in environmental fruits and vegetables samples. Eur. J. Clinical Microbiol. Infect. Dis. 31: 1101-1108.

Lass A., Szostakowska B., Myjak P., Korzeniewski K. 2015 The first detection of Echinococcus multilocularis DNA in environmental fruit, vegetable, and mushroom samples using nested PCR. Parasitol. Res. 114: 4023-4029.
LÉLU M. 2010: Etude d'un parasite à cycle complexe, Toxoplasma gondii: variabilité du cycle de transmission et dynamique de la phase environnementale. PhD thesis, Reims Champagne Ardenne University, Reims, 209 pp.

Lélu M., Gilot-Fromont E., Aubert D., Richaume A., Afonso E., Dupuis E., Gotteland C., Marnef F., Poulle M.-L., Dumètre A., Thulliez P., Dardé M.-L., Villena I. 2011: Development of a sensitive method for Toxoplasma gondii oocyst extraction in soil. Vet. Parasitol. 183: 59-67.

Lélu M., Villena I., Darde M.-L., Aubert D., Geers R., Dupuis E., Marnef F., Poulle M.-L., Gotteland C., Dumetre A., Gilot-Fromont E. 2012: Quantitative estimation of the viability of Toxoplasma gondii oocysts in soil. App. Environ. Microbiol. 78: 5127-5132.

Litt J.S., Soobader M.-J., Turbin M.S., Hale J.W., Buchenau M., Marshall J.A. 2011: The influence of social involvement, neighborhood aesthetics, and community garden participation on fruit and vegetable consumption. Am. J. Public Health. 101: 1466-1473.

Marchesi P., Blant M., Capt S. (Eds.) 2008: Faune-Helvetica. Mammifères de Suisse - Clé de Détermination. CSCF \& SSBF, Neuchâtel, 294 pp.

MARSH R. 1998: Building on traditional gardening to improve household food security. Food Nutr. Agric. 22: 4-14.

Piarroux M., Piarroux R., Knapp J., Bardonnet K., Dumortier J., Watelet J., Gerard A., Beytout J., Abergel A., Bresson-Hadni S., Gaudart J., for the FrancEchino Surveillance Network 2013: Populations at risk for alveolar echinococcosis, France. Emerg. Infect. Dis. 19: 721-728.

Pleydell D.R.J., Raoul F., Tourneux F., Danson F.M., Graham A.J., Craig P.S., Giraudoux P. 2004: Modelling the spatial distribution of Echinococcus multilocularis infection in foxes. Acta Trop. 91: 253-265.

Pusenius J., Vittala J. 1993: Varying spacing behaviour of breeding field voles, Microtus agrestis. Ann. Zool. Fenn. 30: 143-152.

Quintaine T. 2010: Ecologie de la transmission d'Echinococcus multilocularis: Identification des milieux propices et modélisation de l'effet du comportement de l'hôte définitif, Vulpes vulpes. $\mathrm{PhD}$ thesis, Franche-Comté University, Besançon, $146 \mathrm{pp}$.

R Core Team 2015: R: A language and environment for statistical computing. R Foundation for Statistical Computing, Vienna. http://www.R-project.org/

Reperant L.A., Hegglin D., Tanner I., Fischer C., Deplazes P. 2009: Rodents as shared indicators for zoonotic parasites of carnivores in urban environments. Parasitology 136: 329-337.

Reyes-García V., Aceituno L., Vila S., Calvet-Mir L., Garnatje T., Jesch A., Lastra J.J., Parada M., Rigat M., Vallès J., Pardo-De-Santayana M. 2012: Home gardens in three mountain regions of the Iberian Peninsula: description, motivation for gardening, and gross financial benefits. J. Sustain. Agr. 36: 249-270.

Robardet E., Giraudoux P., Caillot C., Augot D., Boue F., BARRAT J. 2011: Fox defecation behaviour in relation to spatial distribution of voles in an urbanised area: an increasing risk of transmission of Echinococcus multilocularis? Int. J. Parasitol 41: 145-154.

Robert-Gangneux F., Aubert D., Villena I. 2015: Toxoplasmosis: a widespread zoonosis diversely affecting humans and animals. In: A. Sing (Ed.), Zoonoses - Infections Affecting Humans and Animals: Focus on Public Health Aspects. Springer, Dordrecht, pp. 355-376.

Simon J.A., Kurdzielewicz S., Jeanniot E., Dupuis E., Marnef M., Aubert D., Villena I., Poulle M.-L. 2017: Spatial distribution of soil contaminated with Toxoplasma gondii oocysts in relation to the distribution and use of domestic cat defecation sites on dairy farms. Int. J. Parasitol. 47: 357-367.

Spitz F., Le Louarn H., Poulet A., Dassonville R. 1974: Standardisation des piégeages en ligne pour quelques espèces de rongeurs. Rev. Ecol. (Terre \& Vie) 28: 564-578. 
STODDART D.M. 1970: Individual range, dispersion and dispersal in a population of water voles (Arvicola terrestris (L.)). J. Animal. Ecol. 39: 403-425.

Tenter A.M., Heckeroth A.R., Weiss L.M. 2000: Toxoplasma gondii: from animals to humans. Int. J. Parasitol. 30: 1217-1258.

Trachsel D., Deplazes P., Mathis A. 2007: Identification of taeniid eggs in the faeces from carnivores based on multiplex PCR using targets in mitochondrial DNA. Parasitology 134: 911-920.

Umhang G., Forin-Wiart M.-A., Hormaz V., Caillot C., Boucher J.-M., Poulle M.-L., Franck B. 2015: Echinococcus multilocularis detection in the intestines and feces of free-ranging domestic cats (Felis s. catus) and European wildcats (Felis s. silvestris) from northeastern France. Vet. Parasitol. 214: 75-79.

Veit P., Bilger B., Schad V., Schäfer J., Frank W., Lucius R. 1995: Influence of environmental factors on the infectivity of Echinococcus multilocularis eggs. Parasitology 110: 79-86.

Vukicevic-Radic O., Matic R., Kataranovski D., StamenkoviC S. 2006: Spatial organization and home range of Apodemus flavicollis and A. agrarius on Mt. Avala, Serbia. Acta Zool. Academ. Sci. Hung. 52: 81-96.

Cite this article as: Bastien M., Vaniscotte A., Combes B., Umhang G., Germain E., Gouley V., Pierlet A., Quintaine T., Forin-Wiart M.-A., Villena I., Aubert D., Boué F., Poulle M.-L. 2018: High density of fox and cat faeces in kitchen gardens and resulting rodent exposure to Echinococcus multilocularis and Toxoplasma gondii. Folia Parasitol. 65: 002. 